\title{
Early Childhood Education and Care in Minority Groups in Canada: Development of Young Aboriginal Children
}

\author{
Lan Wang and Xijun Xu
}

\begin{abstract}
This paper raises awareness of early childhood education and care gap between majority and minority groups in Canada. To address the critical issue in minorities, it analyzes the current situation, and composition of minority groups in Canada grounded on historical perspective. On the basis of the analysis of general early childhood education system in Canada, the diversity between majorities and minorities are reflected through different programs and policies. The Aboriginal group is raised as an example to show the disadvantaged development and the improvement of early care and education under the effort of the federal government and local communities. This paper calls for further study and more attention on early development of children from minorities with the conclusion that the federal government and local communities should cooperate to narrow the gap between majority and minority in a multicultural society.
\end{abstract}

Index Terms-Early childhood education; minority groups; young aboriginal children.

\section{INTRODUCTION}

As a minority group in Canada, young children from the Aboriginal groups raise nationwide concern. A growing numbers of researchers and policymakers are paying more attention to the physical and mental development of the Aboriginal children. The issue of inequality and disadvantage that Aboriginal people have suffered represents the largest clientele in need of early childhood services [1]. The improvement of early education quality in the Aboriginal communities is urgent and necessary. In comparison with majority groups, Aboriginal children stay on a disadvantaged level resulting from dynamic aspects. In Canada, as a multicultural society with diverse groups, the factors such as language and culture barriers, low education attain, and poverty are adverse to Aboriginal children's development.

Early education and care can be considered as the foundation of the whole education system. High-quality education in children's early years has a positive and longitudinal impact on children's academic and social prospects. Early care and education is effective and beneficial to young children's development physically, cognitively and mentally. As well, experience of early education prepares children for school study not only for academic performance but also for social skills. The importance of early childhood education is attracting more attention around the world, even in less-developed countries. To provide young children bright future, Canada has been

Manuscript received May 7, 2018; revised December 12, 2018.

The authors are with the Wuhan University of Technology, China (e-mail: lindawong77@hotmail.com,10876504@qq.com). working on the improvement of children's early education and care for a long time. The purpose of this paper is to address the issue of early education and care for children from minority groups, especially the Aboriginal communities in Canada. Through analyzing the current situation of minority groups in Canada, the problems existing in education system will be discussed. Meanwhile, as a successful program which has improved quality of early care and education in the Aboriginal communities, the Aboriginal Head Start will be introduced.

\section{A LOOK AT MinORITY COMPOSITION IN CANADIAN SOCIETY}

On the basis of the data review by OECD in Early childhood education and care policy: country not for Canada [2], as the second largest country in the world with a land mass of more than nine million square kilometers, Canada is one of the most typical multicultural societies around world. Different from the United States and other immigrant countries, Canada is a bilingual country with two official languages: English and French, resulting from the first wave of settlers primarily from France and Britain. With 31 million populations [2], the coexistence of majority and minority groups in Canadian society results in the diverse demographic composition. Compared with the majority population in Canada, immigrant groups, and Aboriginal communities play a prominent role in the discourses of the minority groups in Canadian society. Both immigrant groups and the Aboriginal communities can mostly represent the current status and living situations such as education quality of minorities in a multicultural country.

With the increase of immigrant population, the original native Canadians, who are known as Aboriginal groups, have been left the majority stage of Canadian society. The original inhabitants of Canada are Inuit on the north and the First Nations. The Aboriginal people makeup $3.3 \%$ of the total population. There are three key characteristics of the Aboriginal population: high birth rate, lowing age, and urbanization. For example, according to Aboriginal Peoples in Canada in 2006, the birth rate of the Aboriginal group is 1.5 times higher than the national average. At the same time, the proportion of the Aboriginal population under 15 is as twice as the proportion of non-Aboriginal groups. As well, around half of Aboriginal people live in urban areas. The rapidly increasing the entire population especially young generation in Aboriginal communities did not contribute to its overall development and get this minority group back on the main stage of Canadian society.

According to a study about Aboriginal communities 
conducted by Nguyen [3], the current situation of Aboriginal communities is the historical consequences of colonialism and Crown. Under the rule of the Crown and British colonialism, the Aboriginal was stripped of their land and "the egalitarian society was changed into a class-based society". The original, stable, and harmonious society structure was ruined. At the same, the Crown and British colonialism also tried to control and change Aboriginal's sense of value through striping native culture and language and transforming Aboriginal youth's mind. Language and culture are the label of a group or community. Loss of their language and culture leads to the decay and identity fuzzification of Aboriginal Communities as well as dependent livelihood on colonizer.

The Aboriginal communities are considered as the most disadvantaged and marginalized group in Canadian society. Similarly as one of the minority groups in Canada, the Aboriginal communities attract less attention than immigrant groups. Spreading across the decades up to the present, Aboriginal peoples are over-represented in the most-socio-economic risk categories. The Aboriginal is synonymous with poverty, lower social class and education attainment and higher unemployment rate. As discussed in the study by Nguyen, there $48 \%$ of Aboriginal youth (ages $15-24)$ had no secondary education while only $26 \%$ of non-Aboriginal youth had no secondary education [3]. Also in this study, in 2007, the unemployment rate between the two Aboriginal groups: who do not have a high school diploma and who have one, was $14.2 \%$ compared to $8.0 \%$ [3]. By melding the two sets of data from this study, it indicates that the quality and attainment of education play a critical role in the improvement of Aboriginal's living standards and current situation. In another words, lacking high level and quality education leads to the poverty and lagging development in Aboriginal groups. That is to say, education can improve the situation of poor employment rate. The present situations of the minority groups in Canada, such as high birth rate and low employment, result in lower quality of lives than the one of majorities. Meanwhile, the existing problems in both immigrant and Aboriginal population contribute to the lagging development of the minority groups. To solve the problems, the very first step is to improve the quality of education in minority communities in Canada.

\section{EARLY CHILDHOOD EDUCATION AND CARE IN ABoriginal COMMUNITIES: CURRENT SitUATION - Aboriginal HeAd Start PROGRAM}

Compared with immigrant groups, the Aboriginal is a more marginalized group in Canadian society. The Aboriginals are facing the critical conflict of their original culture and the majority and dominated culture. Likewise, education system of the Aboriginal population is also suffering the unbalance and inequality. Meanwhile, with the rapidly increasing birth rate in Aboriginal groups, the enlargement of early childhood education and care programs and institutes is needed. Moreover, poverty is one of the essential factors which have an impact on education quality in minority groups. A set of data indicates that in First Nations communities, one out of every four children lives in poverty and forty percent of off-reserve children are under substandard living conditions. Based on the aforementioned historical aspects, the population trend and current living conditions of the Aboriginals, the improvement of early childhood education quality is urgent and necessary not only for children's future but also for the development of the whole Aboriginal communities. To provide Aboriginal children a better development environment, grounded on the problems existing in ECEC system in Aboriginal communities, the improvement can be started from the following aspects: language and culture, quality of teacher, parents and communities, and nutrition, which are reflected from the Aboriginal Head Start program.

Recorded in Aboriginal Head Start Urban and Northern Initiative Report [4], the AHS is a "Health Canada-funded early intervention program focused on meeting the early developmental needs of young Aboriginal children living in urban centres and large northern communities" in 1995. The AHS program consists of six components: Culture and Language, Education, Health, Nutrition, Social Support, and Parental Involvement. The purpose of this program lies in improving the quality of young Aboriginal children's development and providing a better and brighter future for the Aboriginal communities in a multicultural society. As mentioned in this report, the AHS program concentrates on preschool education of 3-5 years old children, which is run by locally Aboriginal non-profit organizations. In this program, preschools are operated four days a week to provide the young Aboriginal children thorough care and education. With the development of the AHS program in Canada, more and more researchers and policy makers are working on the consequence and efficiency of this program. A large number of studies demonstrated that the AHS produced a positive result in the development of the Aboriginal children. For instance, Barrieau and Ireland [5] compared children who attended the AHS program with children who had not participated in this program and came to a conclusion that the outcomes of the AHS program were positive. The result of the study by Barrieau and Ireland indicated that "the AHS children had increased self-esteem and independence and they were better practiced in their Aboriginal language and were more knowledgeable about health and nutrition". In a word, the AHS program influences children's development positively.

As the first section of the AHS program, Culture and Language play an essential role in improving education quality of young Aboriginal children. On the basis of the historical factors which result in the current situation in the Aboriginal communities far behind the majorities in Canada, the protection and development of Aboriginal culture and language are crucial. Language is one of the most typical carriers of culture. As well, culture represents the identity of the community or group. From a historical aspect, to slow down the rate of decay and recover the Aboriginal culture and language are the effective solutions to the backwardness of the Aboriginal communities, especially the development of young Aboriginal children. According to the introduction of Culture and Language in the AHS program in Aboriginal Head Start Urban and Northern Initiative Principles and Guidelines in 1998, the specific purpose of Culture and 
Language section is to "enhance the process of cultural and language revival and retention and children will aspire to learn their respective language and participate in their communities" cultures after AHS" [6]. Learning of local language and culture contributes to cultivating the Aboriginal people's the sense of self-esteem of living in their minority communities. At the same time, the learning process also provides an opportunity to both young Aboriginal children and adults to enhance the knowledge of the history, culture and language of the Aboriginal groups and help them get a better understanding of how to improve the current situation. Consequently, being involved in the AHS program, the learning of Aboriginal language and culture not only improve children's awareness and knowledge of their own culture and language, but also promote the revival of the language and culture in the Aboriginal communities.

With the purpose of encouraging and supporting the Aboriginal children to learn with enthusiasm, education was raised as the second component of the AHS program. In another words, the AHS provides the Aboriginal children an appropriate and comfortable environment in order to foster their desire for life-long learning. That is to say, in this program, children are not simply gain the knowledge. Instead, active and enjoyable learning habit will be built and cultivated, which is the foundation of children's future development. To be specific, preschools in this program are concentrating on improving children's physical, spiritual, emotional and social development.

In this section, qualified teachers in preschools are key roles in how to develop the school readiness of the Aboriginal children. Generally, compared with unqualified early childhood education teachers, qualified teachers can provide children a healthier and more comfortable learning and playing environment on both academic and entertainment level. At the same time, to some point, preschools equipped with qualified teachers are more attractive to parents to send their children to receive early education and care. As for the term of qualified early childhood education teachers, in Canada, to be employed within the early childhood education sector, teachers are required to attain standardized qualifications and get licensed In addition, in the Aboriginal preschools, defined in the study of Aboriginal teachers in Canadian schools by St. Denis [7], qualified and professional the Aboriginal teachers should "value the opportunity to teach Aboriginal culture and history, to foster responsible citizens, to challenge negative stereotypes of Aboriginal people, to serve as role models, and because they believed they could have a positive impact on children". However, shortage of qualifies Aboriginal early education teachers is a crucial problem in early education and care of the Aboriginal children. To solve the problem of unqualified early education teachers in the Aboriginal preschools, the AHS program sponsored various services and projects to provide professional training for teachers to meet the requirement of qualifications in early childhood education area.

Moreover, parental involvement and community support also contribute a lot to the development of early care and education in the Aboriginal groups. Taking the role of children's primary teacher, parents have a great impact on children's early development. On one hand, parents are the models of children that children will imitate their parents' behavior spontaneously. On the other hand, parental involvement in children's early care and education provides an opportunity for both parents and pre-school teachers to communicate and exchange information and ideas with each other. In another words, parental involvement is beneficial to getting a better understanding of children as well as parenting. To improve parenting skills, the AHS program funded several programs activities to encourage and empower parental involvement. For example, the AHS program has parents to be involved in the process of teaching and caring children in preschools.

At the same time, in order to encourage parents to be more active their involvement in children's earl care and education, the AHS program assist the families to access resources and service in the Aboriginal communities. According to Aboriginal Head Start Urban and Northern Initiative Principles and Guidelines, the AHS program will work in cooperation with the local service providers to support Aboriginal children and their families such as local, regional, provincial and national organizations. Andersson [8] introduced the Canada Prenatal Nutrition Program as a community service program which was sponsored by the AHS to "provide prenatal nutrition, health information and counseling for expectant First Nations and Inuit mothers, mothers of newborns, and infants up to one year of age". On the contrast, efforts on improving quality of children's care and education also contribute to strengthening communities. Preston [9] claimed that by focusing on the needs of young children, social ties within the community were strengthened, and community bonding was enhanced. Development of children's early care and education promote the collaboration of local services in the Aboriginal communities.

In addition, to improve physical development of Aboriginal children, the AHS program also involves a component of nutrition. In the AHS program, children will be provided with food that meets the nutritional needs. The AHS program will help children build up an appropriate feeding routine. As well, parents and educators in preschools will learn the importance of nutrition balance in children's early development. Targeted on the nutrition issue of Aboriginal children in Canada, the Aboriginal Food Guide is employed as an instruction which is more specific and more respectful to local traditions and customs than the Canada Food Guide. Through the process of proving meals, both parents and children will cultivate balanced nutrition habits and get a better understanding of the importance of nutrition needs in children's development.

\section{DISCUSSION}

A plenty of programs and policies are designed to close the gap of children's early education between majority and minority groups in Canada. Generally, the gap is reflected from the enrollment of children's early education. Therefore, under the involvement of federal and provincial government, as well as other sectors of society, efforts are put in the reduction enrollment requirements to make sure more children especially from marginalized groups can be replaced 
in early education programs. The Head Start program for Aboriginal children is a representative program for the improvement of education quality of children from minority groups. The focus of the program lies in the encouragement of the Aboriginal children's physical, cognitive and academic development. The influential aspects of children's early education experience are involved in the Aboriginal Head Start program and well developed for children's early education. For instance, the Aboriginal Head Start program encourages the participation of parents and communities in children's early care and education. Community support is associated with children's development. In another words, the higher the quality and degree of social supports and social capital available to a child at a community level the better the child outcomes. In addition, the Aboriginal Head Start Program has a high and strict requirement of the quality of teacher as a guarantee of the quality of children's early education and care. The establishment of the Aboriginal Head Start program contributes to narrow the gap of children's early education experience between minorities and majorities in the multicultural society and encouraged the revival of the First National group.

\section{CONCLUSION}

Canada is a typical multicultural society with diverse groups in this country. The diversity can be reflected from the current education system. With the rapid, comprehensive development in Canadian society, both majority and minority groups get a great progress. By analyzing the current early childhood education and care in Canada, minority groups are still lagging behind the majorities. Resulting from the historical factors, the gap between majorities and minorities still exists. To narrow the gap and balance the disparity, the federal and provincial governments have made steps to improve the living standards and development of minorities. As a typical minority group, the Aboriginal population is experience the positive change of their current situation, such as the improvement of quality of early childhood education aforementioned. At the same time, the analysis of early childhood education in Aboriginal groups calls for more attention from the whole society to help minorities get a better development in the future.

\section{REFERENCES}

[1] Preston, Cottrell, Pelletier, \& Pearce, 2012.

[2] N. Andersson et al., Evaluation of the Canada Prenatal Nutrition Program in First Nations Communities, Ottawa, ON: Assembly of First Nations, 2003.

[3] M. Nguyen, "Closing the education gap: A case for aboriginal early childhood education in Canada, A look at the aboriginal headstart program," Canadian Journal of Education, vol. 34, no. 3, pp. 229-248, 2011.

[4] Aboriginal Head Start Urban and Northern Initiative Principles and Guidelines, 1998, October.

[5] A. Barrieau and D. Ireland, Aboriginal Head Start on Reserve Program: Summary of the Evaluation, Ottawa, ON: Health Canada, 2003.

[6] Aboriginal Head Start Urban and Northern Initiative Report (2000), December 3, 2012.

[7] S. Denis and F. Canadian, "A study of aboriginal teachers' professional knowledge and experience in Canadian schools," Canadian Teachers' Federation, 2010.

[8] N. Andersson et al., Evaluation of the Canada Prenatal Nutrition Program in First Nations Communities, Ottawa, ON: Assembly of First, 2003

[9] J. P. Preston et al.,, Cottrell, 2012.

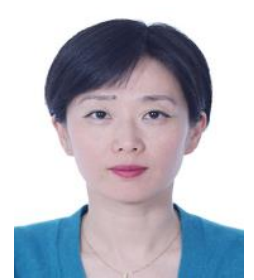

Lan Wang was born in China, 1977. She got the MA in English linguistics and applied linguistics, Central China Normal University, Wuhan, Hubei, China. She has been working as a college English teacher in the Wuhan University of Technology since 2000. And she studied in University of North Carolina at Chapel Hill as a visiting scholar in 2014. The research title is A study on the integration of information technology in English curriculum. The co-author ,Xijun Xu, was born in JiaYu County, Hubei Province, PRC in June, 1979, who has been granted the Bachelor's Degree in English language and literature by Central China Normal University, Wuhan, Hubei, PRC, in 2000 and the master's degree in comparative literature and world literature by Central China Normal University, Wuhan, Hubei, PRC, in 2008.

She has been working as a teacher for Wuhan University of Technology since 2000 . She has published several articles indexed by CPCI.

$\mathrm{Ms}$. $\mathrm{Xu}$ has been the instructor of some significant English competitions, such as "21st Century Cup" National English Speaking Competition and FLTRP Cup National English Competition, including English speaking competition, reading competition and writing competition, etc. 